University of New Hampshire

University of New Hampshire Scholars' Repository

Kinesiology Scholarship

Kinesiology

8-1-2008

\title{
Experience, Reflect, Critique: The End of the "Learning Cycles” Era
}

Jayson O. Seaman

University of New Hampshire, Durham, jayson.seaman@unh.edu

Follow this and additional works at: https://scholars.unh.edu/kinesiology_facpub

Comments

Seaman, J. Experience, reflect, critique: The end of the 'learning cycles' era. Journal of Experiential Education. 31(1),

3-18. Copyright 2008, SAGE Publications. Reprinted by permission of SAGE Publications. https://dx.doi.org/10.1177/

105382590803100103

\section{Recommended Citation}

Seaman, J. (2008). Experience, reflect, critique: The end of the 'learning cycles' era. Journal of Experiential Education. 31(1), 3-18. https://dx.doi.org/10.1177/105382590803100103

This Article is brought to you for free and open access by the Kinesiology at University of New Hampshire Scholars' Repository. It has been accepted for inclusion in Kinesiology Scholarship by an authorized administrator of University of New Hampshire Scholars' Repository. For more information, please contact

Scholarly.Communication@unh.edu. 
Experience, reflect, critique

\title{
Running head: EXPERIENCE, REFLECT, CRITIQUE
}

\author{
Experience, Reflect, Critique: \\ The End of the 'Learning Cycles' Era
}

\author{
Jayson Seaman \\ University of New Hampshire
}

Correspondence concerning this manuscript should be addressed to Jayson Seaman; University of New Hampshire; New Hampshire Hall, 124 Main Street; Durham, NH, 03824. Electronic mail should be sent to jseaman@unh.edu. Fax: (603) 862-0154

Word Count: 6,000 


\title{
Experience, Reflect, Critique: The End of the 'Learning Cycles’ Era
}

\begin{abstract}
According to prevailing models, experiential learning is by definition a stepwise process beginning with direct experience, followed by reflection, followed by learning. It has been argued, however, that stepwise models inadequately explain the holistic learning processes that are central to learning from experience, and that they lack scientific or philosophical foundations. Criticism also centers on the way complex cultural, social, and physical processes during experience and learning are reduced to a rational, excessively cognitive, individual phenomenon. This article reviews this criticism and adds a historical dimension to the analysis, concluding that existing cyclic models might be better valued for their important historical contribution, rather than as active theories of learning in experiential education.
\end{abstract}

Keywords: Experiential learning, outdoor education, adventure education 


\section{Experience, Reflect, Critique: The End of the 'Learning Cycles' Era}

Advocates of outdoor and adventure education would undoubtedly consider their approaches to be robust arenas for experiential learning. For nearly three decades, however, researchers and practitioners have recognized a gap between the transformational learning often witnessed during experiential programs, and the ability of the most common conceptual models and research methods to explain these transformations (e.g., Kraft, 1990; Wichmann, 1980). This has come to be known as the "black box" phenomenon (Baldwin, Persing, \& Magnuson, 2004). On the one hand, the persistence of this gap supports the view that experiential learning may simply be "too mysterious a phenomenon to fully comprehend" (Conrad \& Hedin, 1981, p. 6). On the other hand, it is possible that this gap in knowledge can be attributed to the fundamental way learning has been conceived within these fields.

Experiential learning is typically described within outdoor and adventure education "as a sequential process consisting of several different components, and learning occurs once one has completed the entire sequence" (Wurdinger \& Paxton, 2003, p. 41). Yet the idea that experiential learning is by definition a cycle made up of orderly, sequenced steps is neither eternal nor universally shared. This idea has in fact received considerable criticism in the broader education literature, so much so that the editors of Adult Education Quarterly recently declared it a hindrance to future scholarship. Observing changes in knowledge, research methods, and historical circumstances, they urged readers to "not be caught up short in our thinking and action with unquestioned traditions living on in our work" (Wilson \& Hayes, 2002, p. 175). However, the full weight of this criticism has not been acknowledged in the outdoor and adventure education literature. In fact, the opposite seems to be the case; so central is this conception of 
learning that it underwrites the "first principle" of experiential education: "Experiential learning occurs when carefully chosen experiences are supported by reflection, critical analysis and synthesis" (AEE, n.d.). Given the enduring influence stepwise models have on research and practice in experiential education - even beyond outdoor and adventure education - and given the extent of the criticism they have received elsewhere, it may be prudent to revisit the way learning is unconditionally (albeit often tacitly) defined as a "cycle" or "sequence."

This article reviews the existing criticisms of "learning cycles" and adds a historical dimension to the analysis. Historical analysis creates a useful way to assess an idea's strengths and limitations. It does this by showing how ideas arise out of specific historical conditions and are aimed at solving particular problems, and how they often reflect the values, perspectives, and goals of people working to promote them. Historical analysis also raises the possibility that circumstances and purposes may be different today than before, and that continually relying on inherited assumptions in an uncritical way may shortchange the way educators think about, study, and support learning in outdoor and adventure programs.

While the concept of learning cycles has played a valuable formative role in experiential education to this point, its original purposes and its limits should be observed more carefully when basing research and program designs on it in the future. This is a matter of some urgency given today's "evidence-based" climate (Gass, 2005) and as changing societal demographics and more elaborate program goals require innovations in practice and research. The article closes by noting several ways outdoor and adventure educators in particular can move beyond current conceptual and practical limits.

\section{A History of Ideas}

With regards to outdoor and adventure education, commentary on the mechanics of 
experiential learning is said to begin with Plato (Wurdinger, 1995). Modern understanding of experiential learning, however, derives from more recent influences such as John Dewey's experimental method, Piaget's constructivism, and Kurt Hahn's humanism, along with some combination of behaviorist and cognitive psychology (Hunt, 1990; Kraft, 1990). These underpinnings were formalized as models in the mid- $20^{\text {th }}$ century, when "experiential learning" piqued institutional interest. The prototypical - and most influential (Vince, 1998) - model is Kolb’s (1984) Experiential Learning Cycle (Figure 1).

\section{INSERT FIGURE 1 HERE}

The ideas and models from this era have been characterized as "constructivist perspectives of experiential learning" (Fenwick, 2001). Labeling these models a perspective suggests the possibility of alternatives, and helps mark them off from more established disciplinary traditions. The models comprising this perspective, Fenwick observes, share the assumption "that learning happens through cognitive reflection, experience can be considered like a bounded object, and an individual 'learner' can be separated from his or her experience to process knowledge from that experience" (pp. 7-8). It is helpful to highlight these assumptions upfront to position them as historical artifacts rather than as taken-for-granted truths.

Historical context, theoretical purposes, and ideological commitments. The constructivist perspective of experiential learning developed into a unified set of ideas, if not an ideological movement, in the 1960s and 1970s amidst changing educational and social trends (Keeton, 1976). The models developed during this period served two purposes. The first purpose was predominantly administrative. They were explicitly intended to help colleges devise criteria for awarding credit to adults on the basis of prior life experience, as well as to meet the needs of practitioners using simulation games, role plays, and encounter groups as instructional methods 
(Chickering, 1977; Pearson \& Smith, 1985). The second purpose was moral and social. The movement's pioneers lamented "the dizzying rate of change" characterizing modern society (Kolb, 1984, p. 3) and nostalgically sought to reconnect adults with practical life experience while also empowering them to make positive changes in their lives. They unapologetically infused humanistic values into their conception of learning in order to promote "the development of individuals to their full potential as citizens, family members, and human beings" (Kolb, p. 4).

These purposes are also somewhat conflicting, however. On the one hand, proponents of the constructivist perspective of experiential learning cultivated an educational vision in which "the learner is directly in touch with the realities being studied" (Keeton, in Kolb, 1984, p. 5). In a "hope-filled" manner, they celebrated their commitments to "existential values of personal involvement, and responsibility and humanistic values ... a spirit of inquiry, expanded consciousness and choice, and authenticity in relationships" (Kolb, p. 11).

On the other hand, the legitimacy of experiential learning hinged on the ability to convince educational institutions that adults' lifelong "learning can be reliably assessed and certified for college credit" (Kolb, 1984, p. 3). The Commission on Non-Traditional Study was formed in 1971 to address this issue, resulting in the Cooperative Assessment of Experiential Learning (CAEL). CAEL gathered renowned scholars as well as corporate interests such as the Educational Testing Service to survey the status of experiential learning both as an instructional approach and as a general, existential phenomenon that could be assessed and certified (Keeton, 1976). Their task framed by these two purposes, advocates needed to reconcile adults' ability to learn on their own with the institutional demand for order and predictability. Problematically, interest in experiential learning outpaced the research available to support it on both counts. One contributor to CAEL, sociologist James Coleman (1976), provocatively suggested that learning 
in everyday situations should be valued alongside school learning, yet he noted that his brief comments were "far from definitive ... intended primarily to raise issues for serious examination rather than to provide conclusive prescriptions. The investigation of these matters has a long way to go" (p. 58).

Nearly ten years later, however, Boud, Keough and Walker (1985) still found that the available "learning theory, despite some hopeful signs, has yet to make any substantial contributions to the kinds of learning tasks with which we are normally faced" and they lamented that "many of our remarks cannot be underpinned by the kinds of research we would hope for" (p. 38). The urgent need under these conditions was to develop a conception of experiential learning predictable enough to incorporate "experience" into pre-established categories, yet open-ended enough to convey the humanistic aims of its advocates. The claim that adult learners should "be able to involve themselves fully, openly, and without bias in new experiences" (Kolb, 1984, p. 30) was balanced against the need to demonstrate how "experience" could be institutionally organized, assessed, and certified. The apparent contradiction entailed in this project was either minimized or disregarded. The tension between these two purposes would ultimately be relieved by adopting a narrow conception of experience, and by supplying a cognitive mechanism that could satisfy the condition of self-determination while also providing evidence of creditable knowledge.

Experiential learning in two parts. Experiential learning took shape not as the research program Coleman called for, but as "both a philosophy and a technique, usually focusing on the relationships between an individual, his or her reflective processes, and something called concrete experience" (Fenwick, 2001, p. 8). As Fenwick notes, the emerging conception of experiential learning contained two major aspects. The first was the "here-and-now concrete 
experience" (Kolb, 1984, p. 21). Experience in this sense refers to a time-bounded episode of small group interaction, an instructional technique drawn from T-group training methods that would figure centrally in their conceptual models (Kolb, 1984). The second aspect, individual reflection, was attributed to Lewin, to Dewey, and to Paolo Freire, whose critical views were positioned as the "revolutionary extension of the liberal, humanist perspective" (Kolb, p. 16). The principal aim behind reflection was to accomplish "analytic detachment" (Kolb, p. 9) and "regain our flexibility and creativity in responding to the current situation" (Boud et al., 1985, p. 29).

At first glance, the emancipatory ideals of reflection - something individual adult learners could do "with or without the aid of others" (Boud et al., 1985, p. 26) - seem compelling. Reflection ostensibly provides a means for self-creation in knowledge; finally learners would "have the freedom to make a genuine choice for themselves, rather than conform to the influence of a teacher or other students" (p. 14). But, in keeping with the pressing administrative need to assess and certify adults' experience, reflection also needed to conform to the institutions that would approve and sanction knowledge (Michelson, 1999). For these reasons, reflection could not always be left up to the learner. Boud et al. admit that "there are limits to what each of us can achieve unaided and often the learning process can be considerably accelerated by appropriate support, encouragement, and intervention by others" (p. 36). In order to lay the groundwork for their own proposal, they were, of course, forced to concede "that it is useful for learners and teachers to have a model of reflection which points to some of the major processes which they should consider" (p. 26). The directiveness of what learners "should" consider, the emphasis on "accelerating" the learning process, and the "intervention" of an instructor were apparently not seen as incongruous with the overriding desire for autonomy in 
knowing, captured most clearly in the following passage:

Because we can still learn from our own experience, because we can subject the abstract symbols of the social-knowledge system to the rigors of our own inquiry about these symbols and our own personal experience with them, we are free. This process of choosing to believe is what we feel when we know that we are free to chart the course of our own destiny. (Kolb, 1984, p. 109)

The ambiguity inherent in this perspective may be its greatest asset; a conceptual model such as Kolb's four-stage cycle has tremendous intuitive appeal, adapts handily to various practical applications (e.g., Enns, 1993), and supports a humanistic faith in self-direction. The assumptions behind this perspective, however, derive more from the prevailing ideological and institutional context of adult education in the 1970s than from focused programs of inquiry about the connections between experience and reflection in learning. The selective use of "theoreticians with quite different backgrounds, motives and incompatible conceptions ... as founders and 'supporters' of experiential learning” (Miettinen, 2000, p. 56) allowed early advocates to conflate two opposing ideas: their commitment to the radically autonomous learner, and collectivist and institutional visions for educational "experiences." This ambivalence remains largely unaddressed in current scholarship and may help explain the persistence of the black box phenomenon.

The constructivist perspective of experiential learning is thus revealed not as a rigorous theory of social and mental processes, but as a set of ideas selected from various disciplinary traditions and training regimens in the attempt to "construct an attractive collection of ideas that can be advocated as a solution to the social problems of our time ..." (Miettinen, 2000, p. 56); which, at the time of its founding, were the administrative needs of higher education institutions 
and the ideological interests of the human potential movement (Chickering, 1977).

Furthermore, although these influential authors noted that their claims were not supported by research, their work is often cited as foundational without reference to historical context, ideological background, or theoretical purpose (e.g., Wurdinger \& Priest, 1999). Today, this framework has evolved from a set of practice-driven models with historically specific purposes into a broader belief system underwritten more by liberal-humanist ideology, folk psychology, and administrative interests than by a scientific or epistemological foundation for learning. It has also received considerable criticism in various disciplines such as education, psychology, and philosophy.

\section{Criticism against the Constructivist Perspective of Experiential Learning}

Many of the principles inherent in the constructivist perspective of experiential learning have already received considerable criticism in the outdoor and adventure education literature. Critics in the adult and management education literature - the traditions from which many of these models originated - have focused on more severe methodological and epistemological problems. These challenges will now be reviewed.

Challenges from within outdoor and adventure education. Loynes (2002) argues that the kind of rational, "algorithmic paradigm" sponsored by constructivist models is so pervasive that the field's language, practices, and values largely derive from it, to the exclusion of other alternatives. Bell (1993) observed that many characterizations of experiential education seem preoccupied with individual change and lack "clear sociological analysis" even though the importance of "group identity or culture" (p. 19) is often discussed with respect to participants' learning. Quay (2003) argued that "mechanistic" stepwise models fail to capture the "holistic nature" of experiential learning (p. 108). Similarly, Hovelynck (2001) found outdoor leaders 
developing "practice theories" that better reflect their work once in the field, suggesting that stepwise models may actually inform practice only superficially. Despite these criticisms, the description of experiential learning as "the change in an individual that results from reflection on a direct experience and results in new abstractions and applications" (Itin, 1999, p. 93) remains remarkably durable as a basic concept within outdoor and adventure education, if not all experiential education. These criticisms, however, suggest that this conception of learning cannot meaningfully elaborate the connection between individual and social or physical elements: a connection on which many central claims about outdoor and adventure education depend.

Methodological challenges. One methodological criticism is that early models such as Kolb's (1984) took theorists' ideas out of context and misapplied them to experiencing and learning, thereby narrowing "experience" to fit preconceived institutional categories and instructional methods. According to Miettinen (2000), this tendency resulted in the conceptual "impoverishment" of "the rich variety and modes of human experience characteristic of various human activities" (p. 61). Today, using the concept of "learning cycles" as both a definition of learning and a template for practice enforces a kind of internally reinforcing logic. Althusser's (1964) critique of liberalism is apt here: "while it really does designate a set of existing relations, unlike a scientific concept, it does not provide us with a means of knowing them” (p. 3). Management educators Holman, Pavlica and Thorpe (1997) note the practical dangers with this logic. Speaking of Kolb, they observe:

Such has been his influence, that it appears that when managers 'fail to learn' they are thought by educators to have failed to grasp certain aspects of the learning process (i.e. the learning cycle), but few question experiential learning theory itself or search for alternative explanations. (p. 138. See also Wallace, 1996) 
Finally, Kolb's description of learning styles, a core concept on which his model is based, has been questioned by different authors. Miettinen (2000) argues that Kolb does not effectively show how the "four different kinds of abilities - concrete experience abilities (CE), reflective observation abilities (RO), abstract conceptualizing abilities (AC) and active experimentation abilities (AE)" (Kolb, in Miettinen, p. 61, italics in original) - are related to one another or correspond with phases in a cycle. Miettinen concludes that Kolb's Learning Styles Inventory is simply a training tool and should not be considered a typology of underlying learning mechanisms. Research in cognitive science supports Miettinen's critique; Kirschner, Schweller and Clark (2006) summarize studies showing "that there is little or no correlation between factors that should correlate with the classification of learning styles, and that it [the Learning Styles Inventory] does not enjoy a general acceptance of its usefulness, particularly for research purposes" (p. 81).

Epistemological challenges. There are also epistemological problems with experience and reflection. With regards to experience, Holman et al. (1997) explain how the central concept of direct experience in constructivist models

is seen as pure, unproblematic, fully accessible by conscious thought, possessing a presymbolic quality which exists prior to the meaning attached to it. The text of experience will always be able to be read. Its meaning will always be apparent and decipherable. (p. 138)

Miettinen (2000) critiques this perspective as naïve, noting "the theoretical and epistemological inadequacy of the concept of immediate personal experience" (p. 61) and arguing that there is no such thing as direct experience independent from theories or symbols in the first place. Emerging empirical research in the outdoor and adventure education fields supports this criticism, 
illustrating how experiencing and learning processes are mediated by the physical, social, and discursive conditions of experience (Brown, 2004; Seaman, 2007).

As the radically autonomous learner and the simple "directness" of experience are called into question, reflection as the central act of knowledge production in experiential programs is destabilized and the chronology of "experience-reflect-learn" is not easily maintained as a basic principle of learning. Controversially, evidence suggests that conscious reflection may not play as basic a role in experiential learning as previously believed; research in "social practice" traditions shows how people learn in experience, not from or after it (e.g., Cole, Engeström, \& Vasquez, 1997; Engeström, Mietinnen, \& Punamaki, 2003). These findings, which are far too numerous to list here, make the sentiment "experience alone is not the key to learning" (Boud et al., 1985, p. 7) simply seem strange, if not misguided.

Furthermore, Michelson (1996) suggests that even if reflection could be conceived as merely a mental exercise, one cannot escape social and cultural meanings when one does it (imagine trying to reflect without using language). The rational emphasis in reflection may itself be culturally influenced; for instance, Boud et al. (1985) repeatedly stress that "removing obstructing feelings is a necessary precursor to a rational consideration of events" (p. 26). The presence of obstructing emotions, they write, can "override our rationality to such an extent that we react unawarely and with blurred perceptions" (p. 28). The view that "negative" emotions are to be seen as suspect rather than as crucial insights into the world is a key factor in the argument that experiential learning, as we now know it, is gendered (Fullagar \& Hailstone, 1996; Michelson, 1996). Moreover, such a position is inherently distrustful of bodily experience, an ironic situation for a practice that places a premium on physical interaction and engagement with the natural world. 
Sociocultural challenges. The constructivist perspective of experiential learning is closely linked to Western ideals of individual development. Most notably, Kolb (1984) describes experiential learning as a process of facilitating "growth" and "progress" toward "the highest stages of development" (p. 140), a progression in which learners move "from a state of embeddedness, defensiveness, dependence, and reaction to a state of self-actualization, independence, proaction and self-direction" (p. 140). He takes as his developmental chronology the "ordering of ages at which developmental achievements become possible in the general conditions of contemporary Western culture" (p. 141). This framework, if acknowledged explicitly, could prove instructive to research and program design (cf. Beach, 1999). However, if unrecognized, and if used uncritically as the basic premise for broad claims about experiencing and learning, opens the perspective to charges of ethnocentrism.

From a cross-cultural standpoint, this view may encourage a deficit view of developmental differences pertaining to non-Western cultural traditions. Early research in cultural psychology has been criticized for this very reason, namely that particular forms of abstract reasoning - those common to highly literate societies of European descent - are positioned as a universally advanced developmental state:

Almost all of the well-known "grand theories" of development have specified a single developmental trajectory, moving toward a pinnacle that resembles the values of the theorist's own community or indeed of the theorist's own life-course. For example, theorists who are extremely literate and have spent many years in school often regard literacy and Euro-American school ways of thinking and acting as central to the goals of successful development, and even as defining "higher" cultural evolution of whole societies. (Rogoff, 2003, p. 18) 
Research has shown that abstract knowing is not in fact decontextualized, but instead indicates cognitive functioning typical to persons who have participated extensively in institutionalized schooling and middle-class child rearing practices (Lave, 1993). Cloran (1999) illustrates how the specialized discourse pattern of observe-reflect-generalize in particular indicates extensive participation in these practices rather than a universal communicative or cognitive structure. Again, this recognition could prove helpful to research and program design, but its cultural assumptions should be made overt, rather than being kept hidden.

From a social and political standpoint, the individualism inherent in the constructivist perspective may block efforts to understand mutuality and reciprocity in learning. Michelson (1999) argues:

Underneath the avowal that community is indispensable is a longing for a unitary, authentic self untouched by the demands of human mutuality. ... Experiential learning encourages psychic growth by freeing us from the oppression of other people's choices. Knowles (1990: 42-43) quotes Carl Rogers to the effect that 'I have yet to find the individual who, when he $[\mathrm{sic}]$ examines his situation deeply ... deliberately chooses to have the integrated direction of himself undertaken by another'. (p. 140)

This individualism may also hinder a deeper understanding of the creativity and spontaneity that arises in face-to-face interaction, as "subjectivities that are potentially multiple, shifting, transgressive, and spontaneous are recast as coherent, stable, rational, and self-regulating" (Fenwick, 2001, p. 32). From this view, it is difficult to see how individualistic models of learning can adequately support educational approaches strongly claiming "community" and “perspective taking” as desired outcomes (McKenzie, 2000; Wyatt, 1997).

Finally, from an ecological perspective, Bowers (2005) argues that individualist 
constructivism, which embraces abstract visions of rational, Western progress, intends to "emancipate students from the traditional forms of knowledge that prevent them from entering the modern world" (p. IX); the world of consumerism. By doing so, it tacitly devalues longstanding cultural traditions as backwards and irrelevant. Similarly, it has been suggested that the constructivists" preoccupation with the individual is strongly "tied to social relations of capitalism" and has overtones of discipline and external control (Michelson, in Fenwick, 2001, p. 23). Taken together, these critiques add support to Bowers' (2005) assertion that constructivist theories may unwittingly promote indoctrination by narrowing the broader concepts of experiencing and learning to fit within preconceived institutional, cultural, and moral frameworks without acknowledging their own function in doing so. In Bowers' argument, the effect is an "illusory state of consciousness" ensuring that "both the teachers and students do not know what they do not know" (p. 110), a condition that is presently leading to cultural and environmental degradation. In outdoor and adventure education, Brookes (2002) has put the problem this way: "Realism and individualism are convenient; they exempt outdoor educators from having to know much about nature (it can be perceived directly) or culture (since meaning comes from within the individual rather than from collective memory)" (p. 415).

\section{Implications of these Critiques}

Kirschner et al. (2006) note that constructivism's “emphasis on the practical application of what is being learned seems very positive" (p. 84), yet they encourage educators to move past "the fuzzy and unproductive world of ideology - which sometimes hides under the various banners of constructivism - to the sharp and productive world of theory-based research on how people learn" (p. 84). While it is highly doubtful that theory and research could ever be separated from ideology at any level, their assertion that constructivist models of experiential learning have 
historically been driven more by ideology than by research would appear to have merit.

One implication of the foregoing historical analysis and critical review should be clear: researchers and practitioners might no longer unconditionally accept the definition of experiential learning as a sequence or a cycle. Making continued and unqualified use of this standard definition is problematic for several reasons. First, the most commonly used constructivist models, which have largely become axiomatic with respect to learning in experiential education, were developed under a set of historical circumstances primarily affecting adult education. The extent to which "experience-reflect-learn" patterns apply to experiential learning as it happens with children or as part of compulsory schooling has been taken more as an article of faith than as a proposition that is subject to verification. Researchers might prioritize this issue since it seems central to practice at a very basic level (Russell, 2006). Second, the tendency of constructivist models to dichotomize individual, social, and environmental aspects of learning remains largely unaddressed by researchers in outdoor and adventure education. This is especially problematic since social and physical conditions are believed to play a central role in individual and group learning (Walsh \& Golins, 1976). Bereiter (2002) describes one problem with such individual approaches:

Although cooperation and teamwork are praised, the idea of cooperating in the creation of knowledge never comes to life ... it is hard to deal with the everyday fact of people jointly producing a piece of knowledge that is neither the product of one individual's knowledge or the combination of several individuals' knowledge. Such knowledge is typically an emergent of discourse and cannot be understood at the level of individual interacting minds. (pp. 177-178) 
In other words, constructivist models reduce the highly interactive and bodily qualities of outdoor and adventure experiences to secondary elements in an individual's experience, rather than being constitutive of experience at a more fundamental level.

Third, ample empirical research and philosophical argument (e.g., Fenwick, 2001; Rogoff, Paradise, Meija-Arauz, Correa-Chavez, \& Angelillo, 2003) suggests that the definition of experiential learning as an orderly series of steps either (A) is false, because alternative links between experience and learning can easily be found that do not follow such a pattern and may not emphasize reflection at all, or (B) represents only a narrow type of experiential learning, and thus has limited range outside of specific situations. Therefore, other, more established disciplinary traditions may offer methodological and practical insights at a time when both research and practice face new pressures, and when the gap in our knowledge persists.

\section{Conclusion}

The intent of this article was not to suggest that the routine patterns used in different experiential practices - such as outdoor and adventure programs - in which participants engage in an activity then jointly or individually "reflect," should be abandoned. This straightforward approach has unquestionably served many practitioners throughout the years. However, this article has presented several arguments against the claim that experiential learning can be fundamentally understood as equivalent to these patterns. Moreover, these arguments suggest that the pattern of "experience-reflect-learn" might be considered an ideology of experiential learning rather than a philosophy or a theory of experiential learning. In its time, this framework served a useful purpose. However, given changes in knowledge, research methods, participant populations, societal trends, and educational goals, it may now be influencing research and practice in unhelpful ways. 
One challenge now is to develop conceptions of experiential learning, and methods for studying it, that do not "limit our theorizing and threaten to repress both experiencing and learning processes" (Fenwick, 2001, p. 25). This will require adopting theoretical perspectives that take social and cultural context seriously (cf. Brookes, 2003), that hold promise for guiding instructional practice in increasingly complex applications, and that align with the standards of established scientific and philosophical traditions rather than being based in institutional lore and folk psychology. If experiential education is to play a serious part in the social, educational, and ecological problems of our time, it may be worth moving "alternative" perspectives to a more central role in future inquiry and scholarship. 


\section{References}

AEE. (n.d.). AEE Definition of Experiential Education. Retrieved November 22, 2005, from http://www.aee.org/faq/nfaq.htm\#ee

Althusser, L. (1964). Marxism and humanism. Cahiers de l'I.S.E.A., June.

Baldwin, C., Persing, J., \& Magnuson, D. (2004). The role of theory, research, and evaluation in adventure education. Journal of Experiential Education, 25(3), 167-183.

Beach, K. (1999). Consequential transitions: A sociocultural expedition beyond transfer in education. Review of Educational Research, 24, 101-139.

Bell, M. (1993). What constitutes experience? Rethinking theoretical assumptions. Journal of Experiential Education, 16(1), 19-24.

Bereiter, C. (2002). Education and mind in the knowledge age. Mahwah, NJ: Lawrence Erlbaum and Associates.

Boud, D., Keogh, R., \& Walker, D. (1985). Promoting reflection in learning: A model. In D. Boud, R. Keogh \& D. Walker (Eds.), Reflection: Turning experience into learning (pp. 19-40). New York: Kogan Page.

Bowers, C. A. (2005). The false promises of constructivist learning theories: A global and ecological critique. New York: Peter Lang Publishing.

Brookes, A. (2002). Lost in the Australian bush: Outdoor education as curriculum. Journal of Curriculum Studies, 34(4), 405-425.

Brookes, A. (2003). A critique of neo-Hahnian outdoor education theory. Part one: Challenges to the concept of 'character building'. Journal of Adventure Education and Outdoor Learning, 3(1), 49-62. 
Brown, M. (2004). Let's go round the circle: How verbal facilitation can function as a means of direct instruction. Journal of Experiential Education, 27(2), 161-175.

Chickering, A. (1977). Experience and learning: An introduction to experiential learning. New Rochelle, NY: Change Magazine Press.

Cloran, C. (1999). Contexts for learning. In F. Christie (Ed.), Pedagogy and the shaping of consciousness: Linguistic and social processes (pp. 31-65). London: Cassell.

Cole, M., Engeström, Y., \& Vasquez, O. (Eds.). (1997). Mind, culture, and activity: Seminal papers from the Laboratory of Comparative Human Cognition. New York: Cambridge University Press.

Coleman, J. (1976). Differences between experiential and classroom learning. In M. Keeton (Ed.), Experiential learning: Rationale, characteristics and assessment (pp. 49-61). San Francisco, CA: Jossey Bass.

Conrad, D., \& Hedin, D. (1981). The impact of experiential education: Summary and implications. Journal of Experiential Education, 4(2), 6-20.

Engeström, Y., Mietinnen, R., \& Punamaki, R.-L. (Eds.). (2003). Perspectives on activity theory. Cambridge: Cambridge University Press.

Enns, C. Z. (1993). Integrating separate and connected knowing: The experiential learning model. Teaching of Psychology, 20(1), 7-13.

Fenwick, T. (2001). Experiential learning: A theoretical critique from five perspectives. Ohio State University: ERIC Clearinghouse on Adult, Career, and Vocational Education.

Fullagar, S., \& Hailstone, S. (1996). Shifting the ground: Feminist theory in the outdoors. Social Alternatives, 15(2), 23-27. 
Gass, M. (2005). Comprehending the value structures influencing significance and power behind experiential education research. Journal of Experiential Education, 27(3), 286296.

Holman, R., Pavlica, K., \& Thorpe, R. (1997). Rethinking Kolb's theory of learning in management education. Management Learning, 28(2), 135-148.

Hovelynck, J. (2001). Practice-theories of facilitating experiential learning in Outward Bound: A research report. Journal of Adventure Education and Outdoor Learning, 1(2), 53-57.

Hunt, J. (1990). Philosophy of adventure education. In S. Priest \& J. C. Miles (Eds.), Adventure education (pp. 119-128). State College, PA: Venture Publishing.

Itin, C. (1999). Reasserting the philosophy of experiential education as a vehicle for change in the 21st century. Journal of Experiential Education, 22(2), 91-98.

Keeton, M. (Ed.). (1976). Experiential learning: Rationale, characteristics and assessment. San Francisco, CA: Jossey Bass.

Kirschner, P. A., Sweller, J., \& Clark, R. E. (2006). Why minimal guidance does not work: An analysis of the failure of constructivist, discovery, problem-based, experiential, and inquiry-based teaching. Educational Psychologist, 41(2), 75-86.

Kolb, D. (1984). Experiential learning: Experience as the source of learning and development. Englewood Cliffs, NJ: Prentice-Hall.

Kraft, R. (1990). Experiential learning. In J. C. Miles \& S. Priest (Eds.), Adventure Education (pp. 175-183). State College, PA: Venture Publishing.

Lave, J. (1993). Introduction. In S. Chaiklin \& J. Lave (Eds.), Understanding practice: Perspectives on activity and context (pp. 3-34). Cambridge: Cambridge University Press. 
McKenzie, M. (2000). How are adventure education program outcomes achieved? A review of the literature. Australian Journal of Outdoor Education, 5(1), 19-28.

Michelson, E. (1996). Usual suspects: Experience, reflection and the (en)gendering of knowledge. International Journal of Lifelong Education, 15(6), 438-454.

Michelson, E. (1999). Carnival, paranoia, and experiential learning. Studies in the Education of Adults, 31(2), 140-154.

Miettinen, R. (2000). The concept of experiential learning and John Dewey's theory of reflective thought and action. International Journal of Lifelong Education, 19(1), 54-72.

Pearson, M., \& Smith, D. (1985). Debriefing in experience-based learning. In D. Boud, R. Keough \& D. Walker (Eds.), Reflection: Turning experience into learning (pp. 69-84). London: RoutledgeFalmer.

Rogoff, B. (2003). The cultural nature of human development. New York: Oxford University Press.

Rogoff, B., Paradise, R., Meija-Arauz, R., Correa-Chavez, M., \& Angelillo, C. (2003). Firsthand learning through intent participation. Annual Review of Psychology, 54, 175-203.

Russell, K. (2006). Publishing to the choir or digging deep: Implications of a snapshot of experiential education research. Journal of Experiential Education, 28(3), 243-247.

Seaman, J. (2007). Taking things into account: Learning as kinaesthetically mediated collaboration. Journal of Adventure Education and Outdoor Learning, 7(1), 3-20.

Vince, R. (1998). Behind and beyond Kolb's Learning Cycle. Journal of Management Education, 22(3), 304-319. 
Wallace, M. (1996). When is experiential learning not experiential learning? In G. Claxton (Ed.), Liberating the learner: Lessons for professional development in education (pp. 1631). New York: Routledge.

Walsh, V., \& Golins, G. (1976). The exploration of the Outward Bound process. Unpublished manuscript.

Wichmann, T. F. (1980). Babies and bath water: Two experiential heresies. Journal of Experiential Education, 6-12.

Wilson, A. L., \& Hayes, E. R. (2002). From the editors: The problem of (learning in-from-to) experience. Adult Education Quarterly, 52(3), 173-175.

Wurdinger, S. (1995). Philosophical issues in adventure education. Dubuque, IA: Kendall Hunt. Wurdinger, S., \& Paxton, T. (2003). Using multiple levels of experience to promote autonomy in adventure education students. Journal of Adventure Education and Outdoor Learning, $3(1), 41-48$.

Wurdinger, S., \& Priest, S. (1999). Integrating theory and application in experiential learning. In J. C. Miles \& S. Priest (Eds.), Adventure Programming (pp. 187-192). State College, PA: Venture Publishing.

Wyatt, S. (1997). Dialogue, reflection, and community. Journal of Experiential Education, 20(2), 80-85. 
Figure 1

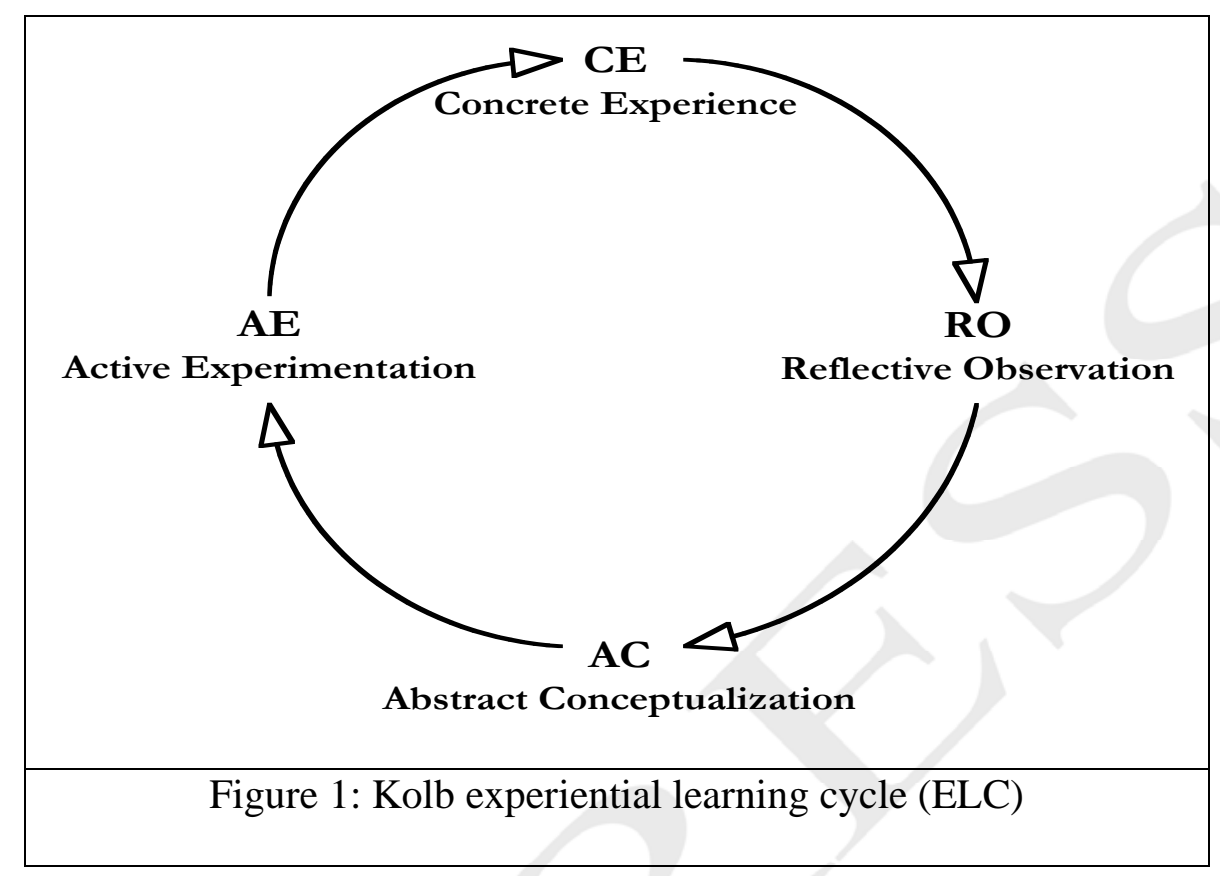

